\title{
A Review of the Novel Application and Potential Adverse Effects of Proton Pump Inhibitors
}

\author{
Li-Yuan Yu · Lu-Ning Sun · Xue-Hui Zhang · Yue-Qi Li • \\ Lei Yu · Zi-Qing-Yun Yuan · Ling Meng · Hong-Wen Zhang • \\ Yong-Qing Wang (D)
}

Received: February 27, 2017 / Published online: April 20, 2017

(C) The Author(s) 2017. This article is an open access publication

\begin{abstract}
Proton pump inhibitors (PPIs) are known as a class of pharmaceutical agents that target $\mathrm{H}^{+}$/ $\mathrm{K}^{+}$-ATPase, which is located in gastric parietal cells. PPIs are widely used in the treatment of gastric acid-related diseases including peptic ulcer disease, erosive esophagitis and gastroesophageal reflux disease, and so on. These drugs present an excellent safety profile and have become one of the most commonly prescribed drugs in primary and specialty care. Except for gastric acid-related diseases, PPIs can also be used in the treatment of Helicobacter pylori infection, viral infections, respiratory system diseases, cancer and so on. Although PPIs are mainly used short term in patients with peptic
\end{abstract}

Enhanced content To view enhanced content for this article go to http://www.medengine.com/Redeem/ E718F0601001E133

L.-Y. Yu · L.-N. Sun · Y.-Q. Li - L. Yu •

Z.-Q.-Y. Yuan · L. Meng · H.-W. Zhang ·

Y.-Q. Wang ( $\triangle)$

Research Division of Clinical Pharmacology, The

First Affiliated Hospital with Nanjing Medical

University, Nanjing, China

e-mail: wyqjsph@163.com

X.-H. Zhang · Y.-Q. Wang

Department of Pharmacy, Jiangsu Shengze Hospital,

Nanjing Medical University, Suzhou, China ulcer disease, nowadays these drugs are increasingly used long term, and frequently for a lifetime, for instance in patients with typical or atypical symptoms of gastroesophageal reflux disease and in NSAID or aspirin users at risk of gastrotoxicity and related complications including hemorrhage, perforation and gastric outlet obstruction. Long-term use of PPIs may lead to potential adverse effects, such as osteoporotic fracture, renal damage, infection (pneumonia and clostridium difficile infection), rhabdomyolysis, nutritional deficiencies (vitamin B12, magnesium and iron), anemia and thrombocytopenia. In this article, we will review some novel uses of PPIs in other fields and summarize the underlying adverse reactions.

Keywords: Adverse effects; Erosive esophagitis; Gastric acid-related diseases; Gastroenterology; Gastroesophageal reflux disease; Helicobacter pylori infection; Peptic ulcer disease; Proton pump inhibitors

\section{INTRODUCTION}

Proton pump inhibitors (PPIs) were first available in 1989 with the discovery of omeprazole; since then they have become one of the most widely prescribed drugs. Currently available PPIs in the USA include omeprazole, 
esomeprazole, lansoprazole, pantoprazole, rabeprazole and dexlansoprazole. Another one called ilaprazole was developed in Korea and is available in China. These drugs have achieved success both clinically and commercially and are indicated for treating various acid-related disorders. Their high potency in increasing gastric $\mathrm{pH}$ coupled with minor side effects has made them very popular.

PPIs are mainly eliminated by the hepatic route and cytochrome P450 (CYP450) system [1]. Polymorphic CYP2C19 and CYP3A4 are the primary enzymes involved in their metabolism [2]. Omeprazole and pantoprazole are metabolized mainly through CYP2C19, which will result in an interaction with other drugs that are also metabolized by the same enzyme such as warfarin and clopidogrel. Lansoprazole is equally metabolized by both CYP2C19 and CYP3A4 and enhances the bioavailability by $30 \%$ by changing the structure to improve the lipotropy. Rabeprazole combines with $\mathrm{H}^{+} /$ $\mathrm{K}^{+}$-ATPase reversibly, causing two- to threefold anti-secretory activity than omeprazole. It is mainly metabolized through non-enzymatic pathways; thus, it has little interaction with other medications [3]. The CYP3A4-selective inhibitors troleandomycin and ketoconazole can significantly increase ilaprazole concentrations in vitro, suggesting that ilaprazole might be dominantly metabolized by CYP3A4 and partly by CYP2C19 [4]. The particular pharmacokinetic and pharmacodynamic characteristics of PPIs are list in Table 1 .

Furthermore, except for acid-related diseases, PPIs are also useful in the treatment of eosinophilic esophagitis, Helicobacter pylori infection, gastric cancer, respiratory system disease and even viral infections. But with extensive application, concerns are raised about serious adverse reactions in long-term use of PPIs. This review is based on previously conducted studies and does not involve any new studies of human or animal subjects performed by any of the authors. In this article, both new applications and adverse reactions of PPIs are reviewed and summarized.

\section{MANAGEMENT OF EOSINOPHILIC ESOPHAGITIS}

Eosinophilic esophagitis (EoE) is now recognized as a chronic allergic inflammatory reaction involving an abnormal Th2-type immunological response. Compared with Western countries, EoE is an uncommon condition in Asia. The prevalence of EoE has been increasing over the past several decades, and reports of this disease are increasingly emerging in both Western and Asian countries [5]. Previously, according to the diagnostic guidelines in 2007, typical EoE did not respond to PPI therapy, and PPIs were considered a diagnostic tool for distinguishing GERD from EoE. However, since the development of the diagnostic guidelines, a growing body of evidence has shown that PPIs might benefit both GERD and EoE patients and has recognized a new potential phenotype of the disease termed PPI-responsive esophageal eosinophilia (PPI-REE) [6].

Since 2005, several case series have reported that patients with clinical, endoscopic and histologic features of EoE were able to achieve high rates of complete remission after an 8-week course of PPIs. Many such cases have been reported, as expected [7]. A systematic review containing 10 randomized clinical trials (RCTs) enrolling 437 patients was performed to assess the efficacy of topical steroids compared with placebo or PPIs for the management of EoE [8]. By analyzing the results, it is not too difficult to see that budesonide was superior to fluticasone (OR 0.96; 95\% CI 0.09-3.92). PPI was superior to fluticasone (OR 0.61; 95\% CI 0.13-1.86) but not to budesonide (OR 1.64; 95\% CI 0.08-8.50). The findings from a meta-analysis even showed that there is no difference between topical steroids and PPIs for most of the symptoms of EoE. There are multiple plausible mechanisms whereby EoE patients benefit from PPI-induced acid suppression: first, acid suppression as well as antiinflammatory effects of PPIs might decrease acid injury-related cytokines, pain, and esophageal permeability. Second, PPIs can inhibit Th2 cytokine-induced eotaxin-3 secretion in esophageal epithelial cells, potentially reducing eosinophil recruitment. Third, PPIs 
Table 1 Pharmacokinetic and pharmacodynamic characteristics of PPIs [82-85]

\begin{tabular}{lllllll}
\hline Agent & Omeprazole & Lansoprazole & Pantoprazole & Rabeprazole & Esomeprazole & Ilaprazole \\
\hline Dosage $(\mathrm{mg} / \mathrm{day})$ & 20 & 30 & 40 & 20 & 40 & 10 \\
Protein binding $(\%)$ & 96 & $97-99$ & 98 & $95-98$ & 97 & $95-96$ \\
Bioavailabiliy & $30-40$ & 91 & 77 & 52 & $64-90$ & 35 \\
Metabolism by & CYP2C19 $>$ & CYP2C19 $=$ & CYP2C19 $>$ & CYP2C19 $=$ & CYP2C19> & CYP3A4 > \\
$\quad$ CYP450 system & CYP3A4 & CYP3A4 & CYP3A4 & CYP3A4 & CYP3A4 & CYP2C19 \\
AUC $(\mu$ mol h/l) & $1.04-2.23$ & $6.52-8.96$ & $5.22-14.90$ & $4.37-4.79$ & $3.88-4.32$ & $4.90-6.00$ \\
$\mathrm{t}_{1 / 2}(\mathrm{~h})$ & $0.50-1.00$ & $1.96-4.21$ & $0.55-2.17$ & $1.76-2.40$ & $0.83-1.20$ & $8.10-10.10$ \\
$\mathrm{~T}_{\text {max }}(\mathrm{h})$ & $0.50-3.50$ & $1.49-3.28$ & $1.10-3.10$ & $2.0-5.00$ & $1.00-3.50$ & $3.40-3.70$ \\
Urinary excretion & 77 & $14-23$ & $71-80$ & 90 & 80 & 80 \\
$\quad(\%)$ & & & & & & 68.90 \\
Time of $\mathrm{pH}>4$ & 49.16 & 47.98 & 41.94 & 50.53 & 58.43 & \\
$\quad(\%)$ & & 3.56 & 3.33 & 3.70 & 4.04 & 4.80 \\
Mean $\mathrm{pH}(24 \mathrm{~h})$ & 3.54 & & & & & \\
\hline
\end{tabular}

$A U C$ area under the plasma concentration-time curve, $t_{1 / 2}$ elimination half-time, Time of $p H>4$ (\%) percentage of time that intragastric $\mathrm{pH}$ is higher than 4 during $24 \mathrm{~h}$

can also exhibit antioxidant properties and inhibit certain functions of immune cells that may contribute to EoE. In conclusion, a trial of PPI therapy might not be suitable for diagnostic purposes, but could be a therapeutic option for EoE [9]. Therapy with PPIs would benefit at least one-third of patients with esophageal eosinophilia, but a case series also reported that EoE might develop during therapy with PPIs [10]. Therefore, it is also necessary to apply other therapies at the same time for some patients.

With the development of treatment for eosinophilic esophagitis in clinical practice, approximately four therapeutic options have become available for treating patients with eosinophilic esophagitis, including dietary modifications (elemental diet, allergy-testing based elimination diet and empiric elimination diet), proton pump inhibitors, topical corticosteroids and endoscopic esophageal dilation. EoE has been recognized as a specific form of food allergy, and dietary modification is straightforward and effective. Corticosteroid therapy as first-line therapy is currently considered the most effective way to treat EoE.

\section{TREATMENT OF HELICOBACTER PYLORI INFECTION}

Helicobacter pylori (H. pylori) is a gram-negative bacillus that parasitizes the human stomach and is the main pathogenic bacterium in protracted gastritis and peptic ulcer disease. $H$. pylori infection is closely connected to chronic active gastritis, peptic ulcer and gastric mucosa-associated lymphoid tissue (MALT) lymphoma. It also plays a crucial role in the pathogenesis of gastric cancer. Eradication of $H$. pylori can not only accelerate ulcer healing, but also reduce the recurrence of ulcers and the risk of gastric cancer. A multicenter, open-label, randomized controlled clinical trial containing 544 patients with early gastric cancer indicated that prophylactic eradication of $H$. pylori prevented the development of metachronous gastric carcinoma. The odds ratio (OR) for 
Table 2 Anti- $H$. pylori strain activity of various PPIs in vitro $[5,6,8,83]$

\begin{tabular}{lrrc}
\hline PPIs & \multicolumn{2}{c}{ MIC $(\boldsymbol{\mu g} / \mathbf{m l})$} & \multirow{2}{*}{ Range $(\boldsymbol{\mu g} / \mathbf{m l})$} \\
\cline { 2 - 3 } & \multicolumn{1}{c}{$\mathbf{5 0 \%}$} & \multicolumn{1}{c}{$\mathbf{9 0 \%}$} & \\
\hline Omeprazole & 25.00 & 50.00 & $12.50-50.00$ \\
Lansoprazole & 6.25 & 12.50 & $3.13-12.50$ \\
Rabeprazole & 0.25 & 1.00 & $0.16-1.00$ \\
Esomeprazole & 16.00 & 32.00 & $8.00-32.00$ \\
Pantoprazole & 50.00 & 100 & $25.00-100$ \\
\hline
\end{tabular}

$M I C$ minimal inhibitory concentration

metachronous gastric carcinoma was 0.35 (95\% CI $0.16-0.76 ; P=0.009$ ), and the hazard ratio (HR) was $0.34(95 \%$ CI $0.16-0.73 ; P=0.003)$, respectively [11].

Benzimidazoles such as omeprazole and lansoprazole show strong activity against $H$. pylori strains in vitro [12] (activities listed in Table 2). The antibacterial activity of PPIs may reside in their structural similarity to imidazoles (metronidazole for instance) and/or in the anti-urease effect they exert [13]. In addition, all of the substituted benzimidazole derivatives with a pyridine ring exhibited activity to $H$. pylori although the efficacy differs among derivatives. Moreover, the antibacterial activity of the metabolic product of PPIs was stronger than that of their prototypes in vitro [13-15]. The antibacterial activity in vitro is strongest with rabeprazole, followed by lansoprazole, esomeprazole, omeprazole and pantoprazole in that order.

Various antimicrobial agents and PPIs have shown their activity against $H$. pylori in vitro. However, clinical trials of these drugs failed to eradicate $H$. pylori successfully with monotherapy [15]. This phenomenon could be explained as follows: first, most drugs are unstable in the low-pH situation of gastric acid; second, the drug concentration is not high enough to be effective in the deep gastric mucus where the bacterium exists; third, the retention time of PPIs in the stomach is very short [16].
Table 3 Standard triple therapy scheme with eradication rate $[2,14,15]$

\begin{tabular}{lll}
\hline PPIs & Antibiotics & Eradication rate (\%) \\
\hline Omeprazole & Amoxicillin + Clindamycin & $79.0-96.0$ \\
Lansoprazole & Amoxicillin + Clindamycin & 85.5 \\
Rabeprazole & Amoxicillin + Clindamycin & $\geq 85.0$ \\
Esomeprazole & Amoxicillin + Clindamycin & $\geq 85.0$ \\
Pantoprazole & Amoxicillin + Metronidazole & $67.0-86.0$ \\
Ilaprazole & Moxifloxacin + Clindamycin & $\geq 90.5$ \\
\hline
\end{tabular}

There are mono, dual and triple therapies based on PPIs for treating $H$. pylori infections in the clinic. PPIs not only suppress the germs directly, but also increase the gastric $\mathrm{pH}$, which would improve the activity of antimicrobials. The current first-line treatment is triple therapy based on one PPI with two other antibiotics [17]. Triple therapies are commonly used, and their eradication rates are listed in Table 3. Other PPIs showed a better eradication effect compared to omeprazole: the most effective combination is based on lansoprazole. Replacement with pantoprazole resulted in fewer adverse reactions, and substitution with rabeprazole led to a higher rate of ulcer healing. Saito et al. conducted a clinical trial involving 80 Japanese patients with gastritis and reported that the $H$. pylori eradication rate of esomeprazole-based triple therapy was similar to those based on other first-generation PPIs [18].

However, the eradication rate of standard triple therapy is declining in most parts of the world [19]. As a general rule, clinicians should prescribe therapeutic regimens that have a per-protocol eradication rate $\geq 90 \%$ for anti- $H$. pylori therapy [20]. With the rising incidence of antimicrobial resistance, the success rate of standard triple therapy reaches almost $80 \%$ in many countries [21]. In two recent randomized controlled trials, the 7-day standard triple therapy had a cure rate of $82 \%$, and the 14-day standard triple therapy achieved an eradication rate of $87 \%$, which implied that new therapeutic methods are needed [22, 23]. Currently, bismuth-containing quadruple therapy, non-bismuth quadruple therapy and 
susceptibility-guided therapy are the new trends for patients who fail to eradicate $H$. pylori with standard triple therapy. Non-bismuth quadruple therapy usual includes sequential, concomitant therapy, hybrid therapy [24] (proposed by Graham and Hsu) and reverse hybrid therapy. Hsu et al. conducted a randomized controlled trial comparing the effect of triple, sequential and concomitant therapies, concluding that the 7-day concomitant therapy had a higher eradication rate than the 7-day triple therapy, but there were no significant differences between sequential and standard triple therapies [25]. Another randomized controlled study involving 440 patients infected with $H$. pylori showed that reverse hybrid therapy resulted in a higher eradication rate with similar tolerability and lower pharmaceutical costs [26]. However, a pooled data analysis revealed that the 10-day sequential treatment regimen achieved higher eradication rates than standard triple therapies [27]. The eradication rate, compliance to the therapy, side effects and cost implications were also compared in this study, and the eradication rate of sequential treatment was constantly higher than $90 \%$.

It is well known that both clarithromycin and metronidazole resistances are the main determinants of treatment failure. The result of a recent study conducted by Liou et al. suggests that $H$. pylori eradication rates are not affected by host CYP2C19 polymorphisms [23]. However, the metabolism of PPIs is considered to be affected by the CYP2C19 genotype to varying degrees, which may also make a difference in the results with the triple therapy. The metabolism of esomeprazole is considered to be little affected by the CYP2C19 genotype: recent studies reported that there were no significant differences in $H$. pylori eradication rates by esomeprazole-based therapy among EM (extensive metabolizer), IM (intermediate metabolizer) and PM (poor metabolizer) of the CYP2C19 genotype, while in another study conducted by Saito, the $H$. pylori eradication rate was significantly lower in CYP2C19 EMs than non-EMs [18]. Therefore, individualized treatment might be very effective in the clinic.

\section{TREATMENT OF VIRAL AND RESPIRATORY SYSTEM DISEASES}

Currently, there are few options for treating viral infections. The most widely used drugs in therapeutic regimens are zidovudine, acyclovir and foscarnet [28]. However, conventional antiviral drugs have shown limitations including a narrow scope of application, serious adverse reactions and drug resistance. There is a great need for new therapies for viral infection. A patent registered by Moorman et al. demonstrated that PPIs exert an antiviral function by effectively inhibiting virus-specific serine proteases [29]. Antiviral effects of PPIs on the herpes virus, major-type rhinovirus and minor-type rhinovirus were later confirmed in other studies $[30,31]$. Omeprazole and esomeprazole were demonstrated to be able to inhibit the entry of Marburg virus and avian influenza H5 in vitro, but the drug concentrations were too high to achieve in vivo [31]. Rhinovirus (RV) can cause the common cold in adults, and patients with bronchitis, bronchopneumonia or chronic respiratory diseases and infants might be particularly vulnerable to it. A randomized, single-blind study was performed and showed that lansoprazole $(15 \mathrm{mg} /$ day $)$ therapy reduces the frequency of common colds and delays the development of chronic obstructive pulmonary disease (COPD) in patients [32].

Concerning the mechanism of the above phenomenon, RV RNA enters across acidic endosomes and increase the mRNA expression of cytokines (including interleukin- $1 \beta$,interleukin-6, interleukin-8 and TNF- $\alpha$ ) and intercellular adhesion molecule-1 (ICAM-1), which is the major RV receptor. Lansoprazole was reported to have suppressing effects on the expression of ICAM-1 mRNA in a way similar to dexamethasone and erythromycin: reducing ICAM-1 expression and increasing endosomal pHby inhibiting $\mathrm{Na}^{+} / \mathrm{H}^{+}$-antiporters and $\mathrm{V}$ ATPase as well as mitigating the viral infection [30].

Moreover, PPIs might have antiinflammatory and antioxidative stress effects [33-35]. The antiinflammatory effects of PPIs are possibly by 
inhibiting production of proinflammatory cytokines [34]. Besides, omeprazole and lansoprazole have been reported to protect human gastric epithelial and endothelial cells against oxidative stress [35]. Exposure to PPIs resulted in a strong induction of heme oxygenase-1 (HO-1) mRNA and protein expression, leading to increased activity of this enzyme. Hence, PPIs might be able to prevent COPD exacerbations, but conclusive evidence is still needed.

Furthermore, $\mathrm{H}^{+} / \mathrm{K}^{+}$-ATPase inhibitors are useful in the treatment of Widal's syndrome as well as related diseases, including nasal polyps, asthma and aspirin intolerance [28]. A possible reason for the treatment of coughs or other respiratory or gastrointestinal complaints caused by gastroesophageal reflux (GER) is that PPIs can decrease the production of proinflammatory cytokines such as IL- 6 , IL- 8 and TNF- $\alpha$ in cultured airway epithelial cells [34]. PPIs are also prescribed to patients with pancreatic diseases such as cystic fibrosis (CF) and pancreatitis as an adjuvant therapy. Among individuals with $\mathrm{CF}$, PPIs are likely initiated for a variety of reasons, but the primary cause is the improved efficacy of pancreatic enzymes in a higher $\mathrm{pH}$ environment $[34,36]$.

\section{TREATMENT OF CANCER}

Tumors are serious problems for human health, and the development of drug resistance has caused widespread failures in cancer treatment. Moreover, recent therapy improvements have been achieved by dose enhancement, but this can lead to severe toxicity and secondary malignancies. Therefore, looking for an effective therapy strategy with low toxicity is the highest priority. PPI-induced tumor cell apoptosis has become a crucial issue worldwide. A previous study suggested that PPIs exert selective apoptosis induction and cytoprotective actions beyond gastric acid suppression [37]. Besides, many studies have demonstrated that PPIs showed antitumor activity both in vitro and in vivo. These remind us that treating tumors could be a novel application for PPIs, especially on multi-drug resistant tumors.
PPIs showed a significant antitumor effect as a single agent in treating melanomas, lymphomas and gastric adenocarcinomas, B cell tumors, multiple myeloma, colorectal cancer, pancreatic cancer and metastatic breast cancer [38-41]. Recently, omeprazole was considered a modulator of tumor chemoresistance, increasing the sensitivity of drug-resistant cancer cells to chemotherapy drugs. Compared to cytotoxic drugs, treatment with PPIs has been proposed as a valid and feasible approach because of their relatively low toxicity and potential selectivity [42]. Because of the acidic microenvironment, it seems conceivable that PPIs may specifically get to the tumor site.

Various studies have been conducted to prove the antitumor effect of PPIs in vitro. Milito et al. showed that PPIs combined with vinblastine could increase the sensitivity to vinblastinein, a pre-B acute lymphoblastic leukemia (ALL) cell line, and dose-dependently inhibit proliferation of tumor B cells, even used alone [38]. Another experiment also revealed that treating human gastric cancer cells with PPIs significantly attenuated cell viability in a time- and dose-dependent manner [39]. A single use of omeprazole can decrease developed multiple colorectal tumors and the incidence of colitis-associated cancer from $75 \%$ to $25 \%$ in mice [37]. The combination of omeprazole and paclitaxel significantly increased the cytotoxicity of paclitaxel. The same effect was found in a chemoresistant epithelial ovarian cancer (EOC) animal model and a patient-derived engraft (PDX) model of clear cell carcinoma [43].

In addition to the in vitro and animal model experiments, PPIs were prescribed both in clinical combination therapy and as a first-line treatment of metastatic melanoma, breast carcinoma and osteosarcoma [44, 45]. Falk et al. confirmed that PPIs plus high-dose aspirin prevented esophageal adenocarcinoma in patients with Barrett's esophagus [46]. The proposed mechanism was that PPIs combined with aspirin may eliminate acid and bile salt reflux or block the activation of gastrin-cholecystekinin (CCK)-cyclooxygenase-2 (COX-2)-mediated pro-carcinogenic signal pathways and regulate PGE2 production. Therapy with PPIs would be a better choice because selective COX-2 inhibitors 
have been shown to increase the risk of thrombotic cardiovascular events.

A multicenter, randomized, phase III clinical trial was conducted to investigate the efficacy of PPIs in terms of improving the clinical outcome of docetaxel combined with a cisplatin regimen in patients with metastatic breast cancer (MBC) [45]. The results of this pilot study showed that intermittent high doses of PPIs enhanced the antitumor effects of antineoplastic drugs with no evidence of additional toxicity. Moreover, the PPI treatment was proven to be particularly efficient in triple-negative breast cancer (TNBC), which currently unfortunately has very limited treatment options. These pilot clinical trials provided a definitive validation for the use of PPIs in future strategies against breast cancer and hopefully in other poorly treatable cancers.

The tumor incidence of the omeprazole group was significantly lower at $63 \%$, while that of the vehicle group was $95 \%$ in an experiment on rats [47]. Gastrin may play an important part in the development of colorectal cancer, and the gastrin concentrations with omeprazole treatment increased nine- to tenfold, which could inhibit cell growth in rats. A recent study confirmed that gastric $H K \alpha 1$ and $H K \beta$ subunits (ATP4A, ATP4B) and non-gastric HKa2 subunits (ATP12A) of $\mathrm{H}^{+} / \mathrm{K}^{+}$-ATPase are expressed in human pancreatic cells, which might be a possible reason for PPIs to regulate the acid-base homeostasis in pancreatic adenocarcinoma [48]. However, not all organizations or cells express $\mathrm{H}^{+} / \mathrm{K}^{+}$-ATPase, and the antitumor effect of PPIs may have other mechanisms.

The Warburg effect is important in tumor growth: cancer cells take in glucose and form lactic acid, which dissociates largely into lactate ions and protons [49]. The acidic metabolites produced from aerobic glycolysis efflux into the extracellular fluid, leading to a low extracellular and high intracellular $\mathrm{pH}$ of cancer cells $[50,51]$. The hypoxic condition and consequent acidity of the tumor microenvironment play a key role in tumor progression, chemoresistance and metastatic behavior [38]. The most probable mechanism of the antitumor effects of PPIs could be explained by inhibiting the acidic microenvironment in cancer. PPIs remarkably disturb the acidic microenvironment and inhibit phosphorylation of the extracellular signal, which regulates kinase $1 / 2$ (ERK1/2), Akt/Src kinases and pyruvate kinase M2 (PKM2), which might also contribute to the induction of apoptosis in cancer cells [52].

Vacuolar-type $\mathrm{H}^{+}$-ATPase (V-ATPase), $\mathrm{Na}^{+} /$ $\mathrm{H}^{+}$exchanger and $\mathrm{Na}^{+}$-dependent $\mathrm{Cl}^{-} / \mathrm{HCO}_{3}{ }^{-}$ are important in alternative or adjunctive strategies for correcting extracellular $\mathrm{pH}$ [53]. A key mechanism of controlling cellular $\mathrm{pH}$ is mediated by V-ATPase, which is located on the surface of the plasma membrane and acidic vesicles such as lysosomes and endosomes [38]. V-ATPase is hypothesized to create a proton efflux and lead to an acidic pericellular microenvironment, promoting the invasive behavior of cancer cells [54]. Several studies have reported that V-ATPase inhibitors such as bafilomycin A and concanamycin A strongly induce apoptotic cell death [55]. Similarly, another study showed that archazolid, another V-ATPase inhibitor, induces anoikis-related pathways in invasive cancer cells [56]. The detected upregulated V-ATPase activity and increased membrane V-ATPase expression in some human tumors are also involved in the chemoresistance and metastatic behavior of cancer cells. Besides targeting the gastric proton pump, PPIs also inhibit the activity of V-ATPase, which can regulate the lysosomal $\mathrm{pH}$, accumulate in lysosomes and perhaps increase the cell sensitivity to cytostatic treatment [41]. Destruction of the acidic microenvironment can not only enhance the effects of cytotoxic agents and reduce multidrug resistance (MDR), but also create domino effects and ultimately lead to the apoptosis of tumor cells $[39,43]$.

PPIs were previously shown to mediate cell death via reactive oxygen species (ROS)-dependent mechanisms. Nicotinamide adenine dinucleotide phosphate (NADPH) oxidase and p38 MAPK were reported to be associated with PPI-induced ROS accumulation [40]. In pancreatic cancer cells, omeprazole works as a selective aryl hydrocarbon receptor (AhR) modulator, while tranilast inhibits invasion through a nongenomic AhR pathway [57]. T-cell-originated protein kinase (TOPK) is a serine-threonine kinase, confirmed to be highly expressed in multiple types of cancer cells such as 
melanoma, lymphoma, colorectal, cholangiocarcinoma, breast, lung cancer and leukemia. TOPK inhibitor has a remarkable antitumor effect [58]. A study containing 1420 patients showed that inhibiting TOPK could benefit $30-40 \%$ patients with metastatic colorectal cancer [58]. However, because of toxicity and poor solubility, two TOPK inhibitors (HI-TOPK-032 and OTS964) have not been used in clinics $[59,60]$. Recent studies indicated that pantoprazole acted as a TOPK inhibitor by directly binding with TOPK both in vitro and in vivo [59]. The inhibition effect of cancer cells by PPIs may indicate a new direction in searching for target therapy, and other mechanisms of the cancer-inhibiting effect are also being investigated.

\section{SOME POTENTIAL ADVERSE EFFECTS OF PPIS}

Generally speaking, PPIs are safe and indicated for multiple well-established and evidence-based diseases. However, patients with gastroesophageal reflux disease need long-term use of PPIs, which are commonly prescribed at large dosages for up to months of administration [61].

A safety alert about a possible increased risk of osteoporosis-related fractures and hypomagnesemia was issued by the FDA in 2010 and 2011 , respectively $[62,63]$. With the wide use of PPIs, concerns about adverse drug reactions (ADRs) to them have been raised worldwide. The most common adverse reactions to PPIs are abdominal pain, diarrhea, constipation, nausea and vomiting. Symptoms of these above-mentioned side effects are tolerable and fade away after stopping the medication. Long-term use of PPIs is also associated with a number of rare but serious adverse effects including nutritional deficiencies (vitamin B12, magnesium and iron), rebound acid hypersecretion, osteoporotic fractures, acute and chronic interstitial nephritis, chronic kidney disease, infection (pneumonia and clostridium difficile infection), rhabdomyolysis, anemia and thrombocytopenia [62-65]. Abundant literature has described the side effects of PPIs by now, and we focus on some of the major ADRs.

\section{Infection}

Recent studies have indicated an increased incidence of community-acquired pneumonia and Clostridium difficile-associated diarrhea in long-term PPI users compared with non-PPI users. A systematic review of eight observational studies found that the overall risk of pneumonia (either community or hospital acquired) was higher among people using PPIs (OR 1.27; 95\% CI 1.11-1.46) [66]. All nested case-control studies showed an increased risk of community-acquired pneumonia associated with PPI use (OR 1.36; 95\% CI 1.12-1.65) [67]. However, a meta-analysis containing 96,870 exposed and 4,141,634 unexposed patients with PPIs indicated that PPIs were not associated with elevation of the risk of community-acquired pneumonia [68]. Therefore, the relationship between PPIs and pneumonia still needs further study.

Another infection associated with PPI therapy is Clostridium difficile infection (CDI), which is a common cause of nosocomial diarrhea, leading to a high risk of morbidity and mortality. A study on 136 patients (19\% community acquired; $81 \%$ healthcare acquired) showed that one of the major risk factors of infection is long-term treatment with PPIs [69]. Mechanistically, the risk of pneumonia and Clostridium difficile infection caused by PPIs remains unclear. One proposed mechanism behind this potential adverse effect is that overgrowing bacteria increase the risk of bacterial aspiration in the stomach and esophagus. More clinical and mechanism studies on the relationship between PPIs and infections are needed.

\section{Hypomagnesemia}

PPI-related hypomagnesemia is rare, but it is recognized as a clinical conundrum because of potential fatal complications. Serious hypomagnesemia-related adverse reactions include tetany, seizure, delirium and cardiac 
arrhythmias. The first case of PPI-induced hypomagnesemia and hypocalcemia was reported in 2006; since then many relevant cases have been published [70-74]. A meta-analysis of nine studies reported a statistically significant effect of PPI therapy on the risk of developing hypomagnesemia (OR 1.76; 95\% CI 1.08-2.92) in 2015 [71].

The average daily intake of magnesium is $300 \mathrm{mg}$ (12 mmol), mostly from green vegetables, nuts, cereals, milk and almonds in particular. There are two main ways of intestinal absorption of magnesium. One is passive transportation via paracellular channels, by which about $7.0 \%$ of magnesium is absorbed; another way is to control active intestinal absorption and possibly to alter the action of transient receptor potential channels (TRPM $6 / 7)$. TRPM6/7 protein plays an important role in the absorption of magnesium, maintaining the magnesium homeostasis when the serum magnesium concentration is low.

The mechanism of hypomagnesemia caused by PPIs is not clear yet. Previous studies discovered that patients with PPI-induced hypomagnesemia also have low fractional excretion of magnesium in the urine, which suggests an extra-renal cause for this electrolyte abnormality $[73,74]$. One possible reason is that TRPM6-mediated magnesium absorption is stimulated by an extracellular proton. A study showed that the amount of intestinal protons increased 3.2 fold in the mid and distal small bowel after esomeprazole administration for over 1 week, which might lead to a compensatory increase in colonic magnesium absorption [75]. PPIs may also lead to an electrolyte abnormality through the effect of hormone levels such as parathyroid hormone.

\section{Osteoporosis}

Many clinical studies have shown a correlation between PPIs and osteoporosis or osteoporosis-related fractures, and PPI therapy increases the risk of osteoporosis-related fractures significantly. Yang et al. conducted a nested case-control study to evaluate the correlation between long-term use of high-dose PPIs and hip fracture, and the results showed that the adjusted odds ratio (AOR) for hip fracture associated with PPI therapy (more than 1 year) was 1.44. The strength of the association improved with increasing duration of PPI therapy (the AOR for 1 year was 1.22 versus 1.59 for 4 years) [76]. Another study proposed a different view, finding that the risk of hip fracture increases mildly after PPI therapy for at least 5 years and the risk of osteoporosis-related fractures increases significantly after PPI use for 7 or more years [77].

A prospective randomized study recruited 26 patients aged between 55 and 85 (PPI group, $n=13$; revaprazan group, $n=13$ ) and showed that PPIs might directly alter the bone metabolism after an 8-week therapy in elderly patients [78]. Another meta-analysis showed that there was no significant statistical difference between fracture risk and histamine 2 receptor antagonists $\left(\mathrm{H}_{2} \mathrm{RAs}\right)$ in 11 studies [79]. The influence on bone metabolism by PPIs is still controversial and has not been fully evaluated. Further studies are required to evaluate the bone-protective treatments for patients with long-term use of PPIs.

Most conclusions about the long-term use of PPIs were based on epidemiological studies, but none of the above-mentioned studies could establish a causal relationship between the PPIs and bone metabolism. Hypotheses about the mechanism of osteoporosis caused by long-term PPI use are as follows: First, decreasing calcium absorption has become the leading cause. According to clinical studies, hypochlorhydria caused by PPI therapy leads to a decrease in calcium absorption in the small intestine and then lower blood calcium [80, 81]. A fall in the blood calcium concentration not only affects bone formation, which is regulated by osteoblasts, but also promotes bone resorption by osteoclasts, followed by a decrease in bone mineral density [81, 82]. Second, PPIs could inhibit the V-ATPase of osteoclasts in the same way that PPIs inhibit gastric $\mathrm{H}^{+} / \mathrm{K}^{+}$-ATPase, having a direct deleterious effect on bone cells, with the possibility of decreased bone turnover [83]. Third, long-term use of PPIs could cause a homocysteine concentration and parathyroid 
hormone increase, which interfere with collagen cross-linking and weaken bone [82].

\section{Renal Adverse Reactions}

The first case in the literature on acute interstitial nephritis (AIN) due to omeprazole was published by Ruffenach in 1992. Subsequent cases have been reported more than 10 years later, such as AIN due to lansoprazole and pantoprazole in 2004 and to rebaprazole and esomeprazole in 2005. Omeprazole was mentioned mostly in the reports of AIN induced by PPIs. An increasing number of studies have been conducted to evaluate the relation between PPIs and the risk of AIN. A population-based cohort study involving nearly 600,000 patients found that those who commenced treatment with PPIs had a twofold greater risk of AIN than patients who were not prescribed this kind of drug [84]. Another study found that relative to past users, current users of PPIs were associated with a significantly increased risk of AIN [85]. Some AIN patients have developed varying degrees of chronic kidney disease (CKD) [86-88]. The risk of CKD is increased in PPI users compared to non-PPI users, and the prevalence is related to the dose and duration of administration.

At present, most scholars believe that common drug-induced AIN has an immunologic basis. Tamm-Horsfall protein, megalin or tubular basement membrane (TBM) may possibly act as endogenous antigens in the development of AIN in some humans. PPI-induced AIN may relate to an immunologic reaction, as indicated by the relatively common appearance of extrarenal manifestations of hypersensitivity. As tubular cells have the capacity to hydrolyze and process exogenous proteins, medications may bind to a normal component of TBM, behaving as a hapten, or mimic an antigen normally present within the TBM and then activate $\mathrm{T}$ helper cells with some stimulating factor by antigen-presenting cell uptake [89]. Finally, they generate a variety of effects, such as activation of killer effect cells and promotion of $B$ cell differentiation, and result in specific antibodies. Renal tubular cells, especially proximal renal tubular cells, are vulnerable to toxic drugs related to the concentration and reabsorption of glomerular filtration. Cytotoxic effects such as mitochondrial dysfunction and increased oxidative stress may lead to cell necrosis and apoptosis. Another possible reason for kidney injury may be ischemic renal failure, caused by the reduced renal blood flow. The possible pathogenesis of renal tubular cell injury may be related to intracellular calcium overload [90]. Due to the high homology of $\mathrm{H}^{+} / \mathrm{K}^{+}$-ATPase and $\mathrm{Ca}^{2+}$-ATPase, PPIs may affect $\mathrm{Ca}^{2+}$-ATPase similarly [91]. Inhibition of intracellular $\mathrm{Ca}^{2+}$ outflow may cause intracellular calcium overload, causing a series of cell death.

\section{Cardiac Adverse Reactions}

PPIs are one of the most important drugs used in open heart cardiac surgery to prevent upper gastrointestinal bleeding. Some in vitro studies on muscle strips and cardiomyocytes showed that PPIs may have negative inotropic effects $[91,92]$. Gastric $\mathrm{H}^{+} / \mathrm{K}^{+}$-ATPase is expressed in human and rabbit myocardium, but pantoprazole did not change the intracellular $\mathrm{pH}$ in an in vitro study [92]. However, pantoprazole can depress cardiac contractility in vitro by depressing the $\mathrm{Ca}^{2+}$ signal and myofilament activity. This could be one of the mechanisms involved in the negative inotropic effects of PPIs.

Another possible reason is that PPIs inhibit the enzymatic activity of dimethylarginine dimethyl aminohydrolase (DDAH), which is responsible for clearing $80 \%$ of asymmetric dimethylarginine (ADMA). A recent pre-clinical study found that PPIs increased the ADMA levels in human endothelial cells and in mice by about 20-30\% [93]. ADMA will impair endothelial NOS (eNOS) via increasing vascular resistance and promoting inflammation and thrombosis. In view of the extensive use of this agent, further studies are necessary to find clinical evidence of negative inotropic effects of PPIs in vivo.

\section{DISCUSSION}

Many factors have been found to affect the efficacy of anti- $H$. pylori therapy, such as 
bacterial resistance to antibiotics, compliance to therapy, genotypes of CYP2C19, and a history of smoking and peptic ulcer. Among these factors, both bacterial clarithromycin resistance and patient compliance play major roles in predicting the therapeutic outcome. Ideal treatments for $H$. pylori infection should be highly efficient, well tolerated and inexpensive. Trials from different areas or patients have shown diverse or even controversial results, indicating that the optimal therapy should be decided according to the local prevalence of antibiotic resistance. It is important to explore more sophisticated systems to evaluate the validity of different regimens in the future. The effects and precise mechanism of other novel uses such as treatment of viruses, respiratory system disease and diabetes need more investigation [94].

Although the role of PPIs in tumor treatment is not fully clear, PPIs combined with cytotoxic drugs as novel alternative antitumor strategies are gaining renewed interest [42]. In addition, most research in this field is still in the in vitro and animal model stage. More clinical studies are needed to evaluate the potential use of PPIs in the treatment of cancer, with the additional purpose of investigating the curative effect of drug combination and adverse reactions.

There is mounting evidence that PPIs are associated with serious adverse effects, especially for those taking high doses. Side effects of long-term use of PPIs are gaining increasing attention. The serum creatinine and magnesium levels should probably be monitored in patients, especially in elderly patients. Moreover, there must be concern about the potential clinically significant drug-drug interactions with these concomitantly administered medications. The FDA updated the methotrexate label, adding the possible drug-drug interaction between high-dose methotrexate and PPIs. There is evidence suggesting that PPIs may decrease methotrexate clearance and elevate the serum concentration, eventually increasing the toxicity [95]. Omeprazoleis is associated with $30 \%$ and $10 \%$ reductions in the systemic clearance of diazepam and phenytoin, and even 50\% or more with ketoconazole and atazanavir [96]. Recently, large-scale clinical trials were conducted on drug-drug interactions between PPIs and clopidogrel [97-99]. PPIs are mainly metabolized by hepatic microsomal enzymes, such as CYP2C19 and CYP3A4, and even have inhibitory effects on them, so care must be taken when combining drugs with PPIs. Additional studies are needed to discover various new applications (both usage and mechanisms) and serious adverse reactions. The evidence for adverse events related to PPIs is limited by the absence of clinical trials and susceptible populations. Research on the mechanism of adverse events is also very poor. From our point of view, the cross-talk effects of PPIs on P-type ATPase $\left(\mathrm{H}^{+} / \mathrm{K}^{+}\right.$-ATPase, $\mathrm{Na}^{+} / \mathrm{K}^{+}$-ATPase, $\mathrm{Ca}^{2+}$-ATPase, et al.) may be one of the possible targets in the mechanism of side effects.

\section{CONCLUSIONS}

PPIs have been used as strong acid suppression agents in clinics for over 20 years and are mainly used in the treatment of acid-related diseases, such as peptic ulcer disease, gastroesophageal reflux disease, NSAID-associated gastrotoxicity and so on. Some of the novel uses of PPIs, such as the treatment of viral infections and respiratory diseases as well as cancer cell suppression, etc., still need more investigation, and most of the studies on the treatment of cancer with PPIs remain in the laboratory (verified in cell or animal experiments). In our opinion, with intensifying research, combination therapy with PPIs can benefit more patients in the near future. However, we need to pay more attention to the potential adverse effects induced by long-term PPI use, especially in the elderly population.

\section{ACKNOWLEDGMENTS}

This project was sponsored by grants from the Priority Academic Program Development of Jiangsu Higher Education Institutions, National Natural Sciences Foundation of China (81673515, 81503160), Natural Science Foundation of Jiangsu Province (BK20161591), Six Talent Peaks Project in Jiangsu Province 
(2014-YY-001) and Jiangsu Provincial Medical Youth Talent (QNRC2016215), Suzhou Science and Education Youth Project (KJXW2016067) and Suzhou Industrial Technology Innovation (SYSD2016046). The article processing charges for this publication were funded by the authors. All named authors meet the International Committee of Medical Journal Editors (ICMJE) criteria for authorship for this manuscript, take responsibility for the integrity of the work as a whole and have given final approval for the version to be published.

Disclosures. Li-Yuan Yu, Lu-Ning Sun, Xue-Hui Zhang, Yue-Qi Li, Lei Yu, Zi-Qing-Yun Yuan, Ling Meng, Hong-Wen Zhang and Yong-Qing Wang declare no conflict of interest.

Compliance with Ethics Guidelines. This article is based on previously conducted studies and does not involve any new studies of human or animal subjects performed by any of the authors.

Open Access. This article is distributed under the terms of the Creative Commons Attribution-NonCommercial 4.0 International License (http://creativecommons.org/licenses/ by-nc/4.0/), which permits any noncommercial use, distribution, and reproduction in any medium, provided you give appropriate credit to the original author(s) and the source, provide a link to the Creative Commons license, and indicate if changes were made.

\section{REFERENCES}

1. Feng S, Cleary Y, Parrott N, Hu P, Weber C, Wang Y, et al. Evaluating a physiologically based pharmacokinetic model for prediction of omeprazole clearance and assessing ethnic sensitivity in CYP2C19 metabolic pathway. Eur J Clin Pharmacol. 2015;71(5):617-24. doi:10.1007/s00228-015-1834$\mathrm{y}$.

2. Wang Y, Zhang H, Meng L, Wang M, Yuan H, Ou N, et al. Influence of CYP2C19 on the relationship between pharmacokinetics and intragastric $\mathrm{pH}$ of omeprazole administered by successive intravenous infusions in Chinese healthy volunteers. Eur J Clin
Pharmacol. 2010;66(6):563-9. doi:10.1007/s00228010-0821-6.

3. Wang Y, Yuan Y, Meng L, Fan H, Xu J, Zhang H, et al. Study of the pharmacokinetics and intragastric $\mathrm{pH}$ of rabeprazole given as successive intravenous infusion to healthy Chinese volunteers. Eur J Clin Pharmacol. 2011;67(1):25-31. doi:10.1007/ s00228-010-0949-4.

4. Li Y, Zhang W, Guo D, Zhou G, Zhou H, Xiao Z. Pharmacokinetics of the new proton pump inhibitor ilaprazole in Chinese healthy subjects in relation to CYP3A5 and CYP2C19 genotypes. Clinica Chimica Acta. 2008;391(1-2):60-7. doi:10.1016/ j.cca.2008.02.003.

5. Abe Y, Sasaki Y, Yagi M, Yaoita T, Nishise S, Ueno Y. Diagnosis and treatment of eosinophilic esophagitis in clinical practice. Clin J Gastroenterol. 2017;10(2):87-102.

6. Lipka S, Muhammad A, Champeaux A, Richter JE. Case report of proton pump inhibitor responsive esophageal eosinophilia: why 2 months of proton pump inhibitors is required. Dis Esophagus. 2016;29(6):700-3. doi:10.1111/dote.12237.

7. Gonzálezcervera J, Lucendo AJ. Eosinophilic esophagitis: an evidence-based approach to therapy. J Investig Allergol Clin Immunol. 2016;26(1):8.

8. Lipka S, Kumar A, Miladinovic B, Richter JE. Systematic review with network meta-analysis: comparative effectiveness of topical steroids vs. PPIs for the treatment of the spectrum of eosinophilic oesophagitis. Aliment Pharmacol Ther. 2016;43(6):663-73.

9. Cheng E. Translating new developments in eosinophilic esophagitis pathogenesis into clinical practice. Curr Treat Options Gastroenterol. 2015;13(1):30-46.

10. Orel R, Murch S, Amil DJ, Vandenplas Y, Homan M. Eosinophilic esophagitis that develops during therapy with proton pump inhibitors: case series and possible mechanisms. Acta Gastroenterol Belg. 2016;79(2):245-50.

11. Fukase $\mathrm{K}$, Kato M, Kikuchi S, Inoue $\mathrm{K}$, Uemura N, Okamoto $\mathrm{S}$, et al. Effect of eradication of Helicobacter pylori on incidence of metachronous gastric carcinoma after endoscopic resection of early gastric cancer: an open-label, randomised controlled trial. Lancet (London, England). 2008;372(9636):392-7. doi:10.1016/s0140-6736 (08)61159-9.

12. Iwahi T, Satoh H, Nakao M, Iwasaki T, Yamazaki T, Kubo K, et al. Lansoprazole, a novel benzimidazole proton pump inhibitor, and its related compounds 
have selective activity against Helicobacter pylori. Antimicrob Agents Chemother. 1991;35(3):490-6.

13. Gatta L, Perna F, Figura N, Ricci C, Holton J, D'Anna $\mathrm{L}$, et al. Antimicrobial activity of esomeprazole versus omeprazole against Helicobacter pylori. J Antimicrob Chemother. 2003;51(2):439-42.

14. Kawakami Y, Akahane T, Yamaguchi M, Oana K, Takahashi Y, Okimura Y, et al. In vitro activities of rabeprazole, a novel proton pump inhibitor, and its thioether derivative alone and in combination with other antimicrobials against recent clinical isolates of Helicobacter pylori. Antimicrob Agents Chemother. 2000;44(2):458-61.

15. Nakao M, Malfertheiner P. Growth inhibitory and bactericidal activities of lansoprazole compared with those of omeprazole and pantoprazole against Helicobacter pylori. Helicobacter. 1998;3(1):21-7.

16. Zhao S, Lv Y, Zhang JB, Wang B, Lv GJ, Ma XJ. Gastroretentive drug delivery systems for the treatment of Helicobacter pylori. World J Gastroenterol. 2014;20(28):9321-9. doi:10.3748/wjg.v20. i28.9321.

17. Zhang Z, Liu ZQ, Zheng PY, Tang FA, Yang PC. Influence of efflux pump inhibitors on the multidrug resistance of Helicobacter pylori. World J Gastroenterol. 2010;16(10):1279-84.

18. Saito Y, Serizawa H, Kato Y, Nakano M, Nakamura $\mathrm{M}$, Saito $\mathrm{H}$, et al. First-line eradication for Helicobacter pylori-positive gastritis by esomeprazole-based triple therapy is influenced by CYP2C19 genotype. World J Gastroenterol. 2015;21(48): 13548-54. doi:10.3748/wjg.v21.i48.13548.

19. Liou JM, Wu MS, Lin JT. Treatment of Helicobacter pylori infection: where are we now? J Gastroenterol Hepatol. 2016;31(12):1918-26. doi:10.1111/jgh. 13418.

20. Rimbara E, Fischbach LA, Graham DY. Optimal therapy for Helicobacter pylori infections. Nat Rev Gastroenterol Hepatol. 2011;8(2):79-88. doi:10. 1038/nrgastro.2010.210.

21. Chuah SK, Tsay FW, Hsu PI, Wu DC. A new look at anti-Helicobacter pylori therapy. World J Gastroenterol. 2011;17(35):3971-5. doi:10.3748/wjg.v17. i35.3971.

22. Gisbert JP, Calvet X. Review article: non-bismuth quadruple (concomitant) therapy for eradication of Helicobater pylori. Aliment Pharmacol Ther. 2011;34(6):604-17. doi:10.1111/j.1365-2036.2011. 04770.x.

23. Liou JM, Chen CC, Chen MJ, Chen CC, Chang CY, Fang YJ, et al. Sequential versus triple therapy for the first-line treatment of Helicobacter pylori: a multicentre, open-label, randomised trial. Lancet (London, England). 2013;381(9862):205-13. doi:10.1016/s0140-6736(12)61579-7.

24. Hsu PI, Lin PC, Graham DY. Hybrid therapy for Helicobacter pylori infection: a systemic review and meta-analysis. World J Gastroenterol. 2015;21(45):12954.

25. Hsu PI, Wu DC, Chen WC, Tseng HH, Yu HC, Wang $\mathrm{HM}$, et al. Randomized controlled trial comparing 7-day triple, 10-day sequential, and 7-day concomitant therapies for Helicobacter pylori infection. Antimicrob Agents Chemother. 2014;58(10):5936-42. doi:10.1128/aac.02922-14.

26. Hsu PI, Kao SS, Wu DC, Chen WC, Peng NJ, Yu HC, et al. A randomized controlled study comparing reverse hybrid therapy and standard triple therapy for Helicobacter pylori infection. Medicine. 2015;94(48):e2104. doi:10.1097/md.00000000000 02104.

27. Zullo A, De Francesco V, Hassan C, Morini S, Vaira D. The sequential therapy regimen for Helicobacter pylori eradication: a pooled-data analysis. Gut. 2007;56(10):1353-7. doi:10.1136/gut.2007.125658.

28. Li H, Meng L, Liu F, Wei JF, Wang YQ. $\mathrm{H}^{+}$/ $\mathrm{K}^{+}$-ATPase inhibitors: a patent review. Expert Opin Ther Pat. 2013;23(1):99-111. doi:10.1517/ 13543776.2013.741121.

29. Moormann AEBDP, Flynn DL, Hui LI, Villamil CI, Inventor method of using $\left(\mathrm{H}^{+} / \mathrm{K}^{+}\right)$ATPase inhibitors as antiviral agents. United States1999 Jun. 14, 2005.

30. Sasaki T, Yamaya M, Yasuda H, Inoue D, Yamada M, Kubo $\mathrm{H}$, et al. The proton pump inhibitor lansoprazole inhibits rhinovirus infection in cultured human tracheal epithelial cells. Eur J Pharmacol. 2005;509(2-3):201-10. doi:10.1016/j.ejphar.2004. 12.042 .

31. Long J, Wright E, Molesti E, Temperton N, Barclay W. Antiviral therapies against Ebola and other emerging viral diseases using existing medicines that block virus entry. F1000Research. 2015;4:30. doi:10.12688/f1000research.6085.2.

32. Sasaki T, Nakayama K, Yasuda H, Yoshida M, Asamura T, Ohrui T, et al. A randomized, single-blind study of lansoprazole for the prevention of exacerbations of chronic obstructive pulmonary disease in older patients. J Am Geriatr Soc. 2009;57(8):1453-7. doi:10.1111/j.1532-5415.2009.02349.x.

33. Vanfleteren LE, Spruit MA, Wouters EF, Franssen FM. Management of chronic obstructive pulmonary disease beyond the lungs. Lancet Respir Med. 
2016;4(11):911-24. 2600(16)00097-7.

doi:10.1016/s2213-

34. Sasaki T, Nakayama K, Yasuda H, Yamaya M. A new strategy with proton pump inhibitors for the prevention of acute exacerbations in COPD. Ther Adv Respir Dis. 2011;5(2):91-103. doi:10.1177/ 1753465810392264.

35. Becker JC, Grosser N, Waltke C, Schulz S, Erdmann $\mathrm{K}$, Domschke $\mathrm{W}$, et al. Beyond gastric acid reduction: proton pump inhibitors induce heme oxygenase-1 in gastric and endothelial cells. Biochem Biophys Res Commun. 2006;345(3):1014-21. doi:10.1016/j.bbrc.2006.04.170.

36. Dimango E, Walker P, Keating C, Berdella M, Robinson N, Langfelderschwind $\mathrm{E}$, et al. Effect of esomeprazole versus placebo on pulmonary exacerbations in cystic fibrosis. BMC Pulm Med. $2014 ; 14(1): 1-7$.

37. Kim YJ, Lee JS, Hong KS, Chung JW, Kim JH, Hahm $\mathrm{KB}$. Novel application of proton pump inhibitor for the prevention of colitis-induced colorectal carcinogenesis beyond acid suppression. Cancer Prev Res (Philadelphia, Pa). 2010;3(8):963-74. doi:10. 1158/1940-6207.capr-10-0033.

38. De Milito A, Iessi E, Logozzi M, Lozupone F, Spada M, Marino ML, et al. Proton pump inhibitors induce apoptosis of human B-cell tumors through a caspase-independent mechanism involving reactive oxygen species. Can Res. 2007;67(11):5408-17. doi:10.1158/0008-5472.can-06-4095.

39. Yeo M, Kim DK, Park HJ, Cho SW, Cheong JY, Lee KJ. Blockage of intracellular proton extrusion with proton extrusions with proton pump inhibitor induces apoptosis in gastric cancer. Cancer Sci. 2008;99(1):185.

40. Marino ML, Fais S, Djavaheri-Mergny M, Villa A, Meschini S, Lozupone F, et al. Proton pump inhibition induces autophagy as a survival mechanism following oxidative stress in human melanoma cells. Cell Death Dis. 2010;1:e87. doi:10.1038/cddis. 2010.67.

41. Udelnow A, Kreyes A, Ellinger S, Landfester K, Walther P, Klapperstueck T, et al. Omeprazole inhibits proliferation and modulates autophagy in pancreatic cancer cells. PLoS One. 2011;6(5):e20143. doi:10.1371/journal.pone. 0020143 .

42. Canitano A, Iessi E, Spugnini EP, Federici C, Fais S. Proton pump inhibitors induce a caspase-independent antitumor effect against human multiple myeloma. Cancer Lett. 2016;376(2):278-83. doi:10. 1016/j.canlet.2016.04.015.
43. Lee YY, Jeon HK, Hong JE, Cho YJ, Ryu JY, Choi JJ, et al. Proton pump inhibitors enhance the effects of cytotoxic agents in chemoresistant epithelial ovarian carcinoma. Oncotarget. 2015;6(33):35040-50. doi:10.18632/oncotarget.5319.

44. Spugnini EP, Buglioni S, Carocci F, Francesco M, Vincenzi B, Fanciulli M, et al. High dose lansoprazole combined with metronomic chemotherapy: a phase I/II study in companion animals with spontaneously occurring tumors. J Transl Med. 2014;12:225. doi:10.1186/s12967-014-0225-y.

45. Wang BY, Zhang J, Wang JL, Sun S, Wang ZH, Wang LP, et al. Intermittent high dose proton pump inhibitor enhances the antitumor effects of chemotherapy in metastatic breast cancer. J Experimen Clin Cancer Res. 2015;34:85. doi:10.1186/ s13046-015-0194-X.

46. Falk GW, Buttar NS, Foster NR, Ziegler KL, Demars CJ, Romero Y, et al. A combination of esomeprazole and aspirin reduces tissue concentrations of prostaglandin $\mathrm{E}(2)$ in patients with Barrett's esophagus. Gastroenterology. 2012;143(4):917-26. doi:10. 1053/j.gastro.2012.06.044.

47. Penman ID, el-Omar E, McGregor JR, Hillan KJ, O'Dwyer PJ, McColl KE. Omeprazole inhibits colorectal carcinogenesis induced by azoxymethane in rats. Gut. 1993;34(11):1559-65.

48. Wang J, Barbuskaite D, Tozzi M, Giannuzzo A, Sorensen CE, Novak I. Proton pump inhibitors inhibit pancreatic secretion: role of gastric and non-gastric $\mathrm{H}^{+} / \mathrm{K}^{+}$-ATPases. PLoS One. 2015;10(5):e0126432. doi:10.1371/journal.pone. 0126432 .

49. Vander Heiden MG, Cantley LC, Thompson CB. Understanding the Warburg effect: the metabolic requirements of cell proliferation. Science (New York, NY). 2009;324(5930):1029-33. doi:10.1126/ science. 1160809.

50. Hashimoto S, Ishisaki A, Yamato K, Aiko K, Amagasa T, Nishihara T. Intracellular apoptosis-inducing factor is induced by a vacuolar type $\mathrm{H}^{+}$-ATPase inhibitor in B lineage cells. J Cell Physiol. 2001;186(1):65-72. doi:10.1002/10974652(200101)186:1<65:aid-jcp1000>3.0.co;2-x.

51. Shchepina LA, Pletjushkina OY, Avetisyan AV, Bakeeva LE, Fetisova EK, Izyumov DS, et al. Oligomycin, inhibitor of the F0 part of $\mathrm{H}^{+}$-ATP-synthase, suppresses the TNF-induced apoptosis. Oncogene. 2002;21(53):8149-57. doi:10.1038/sj.onc.1206053.

52. Shen Y, Chen M, Huang S, Zou X. Pantoprazole inhibits human gastric adenocarcinoma SGC-7901 cells by downregulating the expression of pyruvate 
kinase M2. Oncol Lett. 2016;11(1):717-22. doi:10. 3892/ol.2015.3912.

53. McCarty MF, Whitaker J. Manipulating tumor acidification as a cancer treatment strategy. Alter Med Rev. 2010;15(3):264-72.

54. Glunde K, Guggino SE, Solaiyappan M, Pathak AP, Ichikawa Y, Bhujwalla ZM. Extracellular acidification alters lysosomal trafficking in human breast cancer cells. Neoplasia (New York, NY). 2003;5(6):533-45.

55. Boyd MR, Farina C, Belfiore P, Gagliardi S, Kim JW, Hayakawa Y, et al. Discovery of a novel antitumor benzolactone enamide class that selectively inhibits mammalian vacuolar-type $\left(\mathrm{H}^{+}\right)$-atpases. J Pharmacol Exp Ther. 2001;297(1):114-20.

56. Schempp CM, von Schwarzenberg K, Schreiner L, Kubisch R, Muller R, Wagner E, et al. V-ATPase inhibition regulates anoikis resistance and metastasis of cancer cells. Mol Cancer Ther. 2014;13(4):926-37. doi:10.1158/1535-7163.mct-130484.

57. Jin UH, Kim SB, Safe S. Omeprazole inhibits pancreatic cancer cell invasion through a nongenomic aryl hydrocarbon receptor pathway. Chem Res Toxicol. 2015;28(5):907-18. doi:10.1021/ tx5005198.

58. Zlobec I, Molinari F, Kovac M, Bihl MP, Altermatt HJ, Diebold J, et al. Prognostic and predictive value of TOPK stratified by KRAS and BRAF gene alterations in sporadic, hereditary and metastatic colorectal cancer patients. $\mathrm{Br} \mathrm{J}$ Cancer. 2010;102(1):151-61. doi:10.1038/sj.bjc.6605452.

59. Kim DJ, Li Y, Reddy K, Lee MH, Kim MO, Cho YY, et al. Novel TOPK inhibitor HI-TOPK-032 effectively suppresses colon cancer growth. Can Res. 2012;72(12):3060-8. doi:10.1158/0008-5472.can$11-3851$.

60. Matsuo Y, Park JH, Miyamoto T, Yamamoto S, Hisada S, Alachkar H, et al. TOPK inhibitor induces complete tumor regression in xenograft models of human cancer through inhibition of cytokinesis. Sci Trans Med. 2014;6(259):259ra145. doi:10.1126/ scitranslmed.3010277.

61. Raghunath AS, O'Morain C, McLoughlin RC. Review article: the long-term use of proton-pump inhibitors. Aliment Pharmacol Ther. 2005;22(Suppl 1):55-63. doi:10.1111/j.1365-2036.2005.02611.x.

62. Schoenfeld AJ, Grady D. Adverse effects associated with proton pump inhibitors. JAMA Intern Med. 2016;176(2):172-4. doi:10.1001/jamainternmed. 2015.7927.
63. Wilhelm SM, Rjater RG, Kale-Pradhan PB. Perils and pitfalls of long-term effects of proton pump inhibitors. Expert Rev Clin Pharmacol. 2013;6(4):443-51. doi:10.1586/17512433.2013. 811206.

64. Parikh N, Howden CW. The safety of drugs used in acid-related disorders and functional gastrointestinal disorders. Gastroenterol Clin North Am. 2010;39(3):529-42. doi:10.1016/j.gtc.2010.08.009.

65. Abraham NS. Proton pump inhibitors: potential adverse effects. Curr Opin Gastroenterol. 2012;28(6):615-20. doi:10.1097/MOG.0b013e328 $358 \mathrm{~d} 5 \mathrm{~b} 9$.

66. Eom CS, Jeon CY, Lim JW, Cho EG, Park SM, Lee KS. Use of acid-suppressive drugs and risk of pneumonia: a systematic review and meta-analysis. CMAJ. 2011;183(3):310-9. doi:10.1503/cmaj.092129.

67. Johnstone J, Nerenberg K, Loeb M. Meta-analysis: proton pump inhibitor use and the risk of community-acquired pneumonia. Aliment Pharmacol Ther. 2010;31(11):1165-77. doi:10.1111/j.13652036.2010.04284.x.

68. Filion KB, Chateau D, Targownik LE, Gershon A, Durand M, Tamim H, et al. Proton pump inhibitors and the risk of hospitalisation for community-acquired pneumonia: replicated cohort studies with meta-analysis. Gut. 2014;63(4):552-8. doi:10.1136/ gutjnl-2013-304738.

69. Ogielska M, Lanotte P, Le Brun C, Valentin AS, Garot D, Tellier AC, et al. Emergence of community-acquired Clostridium difficile infection: the experience of a French hospital and review of the literature. Int J Infect Dis. 2015;37:36-41. doi:10. 1016/j.ijid.2015.06.007.

70. Eyal A, Sueissa A, Braun E, Naffaa ME. From hypomagnesaemia to Zollinger-Ellison syndrome: an adverse effect of a proton pump inhibitor. BMJ case reports. 2014. doi:10.1136/bcr-2014-205165.

71. Park $\mathrm{CH}$, Kim EH, Roh YH, Kim HY, Lee SK. The association between the use of proton pump inhibitors and the risk of hypomagnesemia: a systematic review and meta-analysis. PLoS One. 2014;9(11):e112558. doi:10.1371/journal.pone. 0112558

72. Atkinson NS, Reynolds DJ, Travis SP. 'Lemonade Legs': why do some patients get profound hypomagnesaemia on proton-pump inhibitors? Intest Res. 2015;13(3):227-32. doi:10.5217/ir.2015.13.3. 227.

73. Mackay JD, Bladon PT. Hypomagnesaemia due to proton-pump inhibitor therapy: a clinical case 
series. QJM. 2010;103(6):387-95. doi:10.1093/ qjmed/hcq021.

74. Furlanetto TW, Faulhaber GA. Hypomagnesemia and proton pump inhibitors: below the tip of the iceberg. Arch Intern Med. 2011;171(15):1391-2. doi:10.1001/archinternmed.2011.199.

75. Bai JP, Hausman E, Lionberger R, Zhang X. Modeling and simulation of the effect of proton pump inhibitors on magnesium homeostasis. 1. Oral absorption of magnesium. Mol Pharm. 2012;9(12):3495-505. doi:10.1021/mp300323q.

76. Yang YX, Lewis JD, Epstein S, Metz DC. Long-term proton pump inhibitor therapy and risk of hip fracture. JAMA. 2006;296(24):2947-53. doi:10. 1001/jama.296.24.2947.

77. Targownik LE, Lix LM, Metge CJ, Prior HJ, Leung S, Leslie WD. Use of proton pump inhibitors and risk of osteoporosis-related fractures. CMAJ. 2008;179(4):319-26. doi:10.1503/cmaj.071330.

78. Jo Y, Park E, Ahn SB, Jo YK, Son B, Kim SH, et al. A proton pump inhibitor's effect on bone metabolism mediated by osteoclast action in old age: a prospective randomized study. Gut liver. 2015;9(5):607-14. doi:10.5009/gnl14135.

79. Eom CS, Park SM, Myung SK, Yun JM, Ahn JS. Use of acid-suppressive drugs and risk of fracture: a meta-analysis of observational studies. Ann Fam Med. 2011;9(3):257-67. doi:10.1370/afm.1243.

80. O'Connell MB, Madden DM, Murray AM, Heaney RP, Kerzner LJ. Effects of proton pump inhibitors on calcium carbonate absorption in women: a randomized crossover trial. Am J Med. 2005;118(7):778-81. doi:10.1016/j.amjmed.2005.02.007.

81. Serfaty-Lacrosniere C, Wood RJ, Voytko D, Saltzman JR, Pedrosa M, Sepe TE, et al. Hypochlorhydria from short-term omeprazole treatment does not inhibit intestinal absorption of calcium, phosphorus, magnesium or zinc from food in humans. J Am Coll Nutr. 1995;14(4):364-8.

82. Boyce BF. Stomaching calcium for bone health. Nat Med. 2009;15(6):610-2. doi:10.1038/nm0609-610.

83. Costa-Rodrigues J, Reis S, Teixeira S, Lopes S, Fernandes $\mathrm{MH}$. Dose-dependent inhibitory effects of proton pump inhibitors on human osteoclastic and osteoblastic cell activity. FEBS J. 2013;280(20):5052-64. doi:10.1111/febs.12478.

84. Antoniou T, Macdonald EM, Hollands S, Gomes T, Mamdani MM, Garg AX, et al. Proton pump inhibitors and the risk of acute kidney injury in older patients: a population-based cohort study. CMAJ
Open. 2015;3(2):E166-71. doi:10.9778/cmajo. 20140074.

85. Blank ML, Parkin L, Paul C, Herbison P. A nationwide nested case-control study indicates an increased risk of acute interstitial nephritis with proton pump inhibitor use. Kidney Int. 2014;86(4):837-44. doi:10.1038/ki.2014.74.

86. Praga M, Sevillano A, Aunon P, Gonzalez E. Changes in the aetiology, clinical presentation and management of acute interstitial nephritis, an increasingly common cause of acute kidney injury. Nephrol Dial Transplant. 2015;30(9):1472-9. doi:10.1093/ndt/gfu326.

87. Klassen S, Krepinsky JC, Prebtani AP. Pantoprazole-induced acute interstitial nephritis. CMAJ. 2013;185(1):56-9. doi:10.1503/cmaj.120954.

88. Xie Y, Bowe B, Li T, Xian H, Balasubramanian S, Al-Aly Z. Proton pump inhibitors and risk of incident CKD and progression to ESRD. J Am Soc Nephrol. 2016;27(10):3153-63. doi:10.1681/asn. 2015121377.

89. Praga $M$, Gonzalez E. Acute interstitial nephritis. Kidney Int. 2010;77(11):956-61. doi:10.1038/ki. 2010.89 .

90. Qi X, Cai Y, Gong L, Liu L, Chen F, Xiao Y, et al. Role of mitochondrial permeability transition in human renal tubular epithelial cell death induced by aristolochic acid. Toxicol Appl Pharmacol. 2007;222(1):105-10. doi:10.1016/j.taap.2007.03. 029.

91. Schillinger W, Teucher N, Sossalla S, Kettlewell S, Werner C, Raddatz D, et al. Negative inotropy of the gastric proton pump inhibitor pantoprazole in myocardium from humans and rabbits: evaluation of mechanisms. Circulation. 2007;116(1):57-66. doi:10.1161/circulationaha.106.666008.

92. Sossalla S, Schotola H, Schmitto J, Toischer K, Sohns $\mathrm{C}$, Schworer $\mathrm{H}$, et al. Effects of different proton pump inhibitors on cardiac contractility in isolated human failing myocardium. J Cardiovasc Surg. 2011;52(3):437-44.

93. Shah NH, LePendu P, Bauer-Mehren A, Ghebremariam YT, Iyer SV, Marcus J, et al. Proton pump inhibitor usage and the risk of myocardial infarction in the general population. PLoS One. 2015;10(6):e0124653. doi:10.1371/journal.pone. 0124653.

94. Takebayashi K, Inukai T. Effect of proton pump inhibitors on glycemic control in patients with diabetes. World J Diabetes. 2015;6(10):1122-31. doi:10.4239/wjd.v6.i10.1122. 
95. Bezabeh S, Mackey AC, Kluetz P, Jappar D, Korvick J. Accumulating evidence for a drug-drug interaction between methotrexate and proton pump inhibitors. Oncologist. 2012;17(4):550-4. doi:10. 1634/theoncologist.2011-0431.

96. Ogawa R, Echizen H. Drug-drug interaction profiles of proton pump inhibitors. Clin Pharmacokinet. 2010;49(8):509-33. doi:10.2165/11531320000000000-00000.

97. Andersson T, Nagy P, Niazi M, Nylander S, Galbraith H, Ranjan S, et al. Effect of esomeprazole with/without acetylsalicylic acid, omeprazole and lansoprazole on pharmacokinetics and pharmacodynamics of clopidogrel in healthy volunteers. Am J Cardiovasc Drugs. 2014;14(3):217-27. doi:10. 1007/s40256-014-0073-4.
98. Frelinger $\mathrm{AL}$ 3rd, Lee RD, Mulford DJ, $\mathrm{Wu} \mathrm{J}$, Nudurupati S, Nigam A, et al. A randomized, 2-period, crossover design study to assess the effects of dexlansoprazole, lansoprazole, esomeprazole, and omeprazole on the steady-state pharmacokinetics and pharmacodynamics of clopidogrel in healthy volunteers. J Am Coll Cardiol. 2012;59(14): 1304-11. doi:10.1016/j.jacc.2011.12.024.

99. Leonard CE, Bilker WB, Brensinger CM, Flockhart $\mathrm{DA}$, Freeman CP, Kasner SE, et al. Comparative risk of ischemic stroke among users of clopidogrel together with individual proton pump inhibitors. Stroke. 2015;46(3):722-31. doi:10.1161/strokeaha. 114.006866 . 